\title{
Bovine Trypanosomosis: Prevalence, Vector Density and Livestock Farmers' Perception on the Impact of Trypanosomosis and Tsetse Control Interventions in Arbaminchzuriaworeda, Southern Ethiopia
}

\author{
Firew Lejebo $^{1}$, Esayas Balcha ${ }^{1 *}$, Esayas Estiphanos ${ }^{2}$, Gelano Gehano $^{2}$ \\ ${ }^{1}$ National Institute for Control and Eradication of Tsetse and Trypanosmiasis, Arba Minch, Ethiopia \\ ${ }^{2}$ Livestock and Fisheries Resource, Konso Zone, Ethiopia
}

\begin{abstract}
*Corresponding Author: Esayas Balcha, National Institute for Control and Eradication of Tsetse and Trypanosmiasis, Arba Minch, Ethiopia Email: esayasbalcha@gmail.com
\end{abstract}

\begin{abstract}
A cross sectional study was conducted from October 2015 to April, 2016 to determine post control prevalence of bovine trypanosomosis and density of tsetse and other biting flies and to assess the livestock farmers' perception about the impact of integrated tsetse control interventions implemented by Southern Rrift Valley Tsetse Eradication Project (STEP) in three selected kebeles of Arbaminchzuriaworeda, GamoGofa Zone, in South Nation Nationalities and People Regional state (SNNPR). Entomological, parasitological and questionnaire surveys were carried out in the study area covered by STEP. Both primary and secondary data were used. Structured questionnaire was administered by face to face discussion to 216 randomly selected households to assess the perception of livestock keepers towards the impact of trypanosomosis and its vector control interventions. For parasitological survey, blood samples were collected from 360 randomly sampled cattle and screened by Buffy coat technique for detection of trypanosomes. Giemsa stained thin smear technique was applied on the positive samples for trypanosome species identification. A total of 15 baited monopyramidal NGU traps were deployed for 72 hours to catch flies. The present questionnaire survey has revealed that the livestock keepers in the study area had a good knowledge about the suggestive signs of trypanosomosis and means of transmission and also on the impact of the disease on the agricultural and livestock production and on the livelihood and wellbeing of themselves. The majority of the respondents agreed that the tsetse and trypanosomosis control interventions have reduced the tsetse density and the prevalence of trypanosome infection to a low level. In the present study, out of the 360 examined animals, $6(1.7 \%)$ animals were found positive. The trypanosome species detected were T. congolense (83.3\%) and T. vivax (16.7\%). No significant association was seen between the prevalence of trypanosome infection and the host factors (age, sex, body condition score), kebele of study and altitude ( $p>0.05)$. Regarding entomological survey, a total of 121 tsetse flies and 188 other biting flies (tabanus and Stomoxys) were caught. All of the tsetse flies were identified to be Glossinapallidipes. The overall apparent tsetse flies density in study area was 2.7 flies/trap/day. A considerable reduction in tsetse density and prevalence of trypanosome infection was noted when the present entomological and parasitological survey result was compared to that of the 2010 study on the same study area, In general, the present study has revealed a good correlation between the parasitological, entomological and questionnaire survey findings all of which reflect the actual situation on the ground that there is reduction in tsetse flies density and trypanosomosis prevalence as a result of integrated intervention implemented by STEP.
\end{abstract}

Keywords: Trypanosomosis, prevalence, vector density, tsetse suppressive interventions, STEP, traps, tsetse fly, biting flies

\section{INTRODUCTION}

Livestock keeping among various communities in Africa is a source of livelihood, income, nutrition, traction, manure and pride. Any factor that can lead to poor health or death of livestock is detrimental to the livestock production (Seinfeld et al., 2006). Ethiopia has high

ARC Journal of Animal and Veterinary Sciences livestock resource potential with estimated number of 53.4 million heads of cattle, 25.5 million heads of sheep, 22.78 million heads of goats and more than 858 million equines and 2.3 heads of camels (CSA, 2011). However, much of the livestock resources are not fully utilized to maximum due to various constraints. Major problems are attributed to poor genetic pool, 
poor management (animal husbandry) and animal diseases. Trypanosomosis is one of the major animal diseases affecting sub Saharan African countries in general and Ethiopia in particular (Gebreyohannes and Legesse, 2014). Trypanosomosis is a serious parasitic disease caused by different species of uni-cellular protozoan parasites of the genus trypanosome found in the blood and other tissues of vertebrates including livestock, wild life and people and transmitted cyclically by tsetse flies (Glossina species) (OIE, 2008). It is a serious disease in domestic livestock that causes a significant negative impact in food production and economic growth in many parts of the world (Taylor et al., 2007), particularly in sub-Saharan Africa as a threat to the ongoing effort on poverty alleviation in the continent (Cecchiet al., 2008). Bovine trypanosomiasis is one of the most prevalent and important disease in Ethiopia limiting livestock productivity and agricultural development. Diseased animals exert a heavy economic loss on agricultural production in tsetse-infested areas, with the rural poor bearing a disproportionately larger share of the economic burden due to their reliance on livestock as a form of savings and income (Dagnatchew, 1982).

The disease is very economical because of its highest prevalence in the most arable and fertile land with high potential for agricultural development in the South West and North West part of the country along the great river basins of Abay, Omo, Ghibe and Baro which are infested with vector tsetse fly (Feldmannet al., 2005). In Ethiopia, over 6 million heads of cattle and equivalent number of other livestock species are at risk of contracting trypanosomosis. More than 20,000 heads die per annuam, and annual loss attributed to the disease is estimated to be over US\$236 million, whereas loss due to reduced meat, milk and draft power is not applicable to this figure (OAU, 2002).

The most important Trypanosoma species affecting cattle in Ethiopia are Trypanosomacongolense, Trypanosomavivax and Trypanosomabrucei in cattle, sheep and goats. Camels are affected by Trypansosomaevansi which is common species in camel rearing areas of the country while equines mainly horses are affected by Tryranosomaequiperdum in some highland parts of the country. The tsetse fly species like Glossinamorsitans sub marzipans, G. pallidipes,
G. tachinoides, G. fuscipesfuscipe sand G.longipennis commonly found in different parts of the country (Abebe, 2005). Apart from cyclical transmission of trypanosomosis by Glossinaspecies, mechanical transmission is a potential threat to livestock productivity in some parts of Ethiopia (Abebe and Jobre, 1996). Trypanasomavivax infection can be transmitted mechanically by several Tabanidae and large numbers of biting flies (Radostits et al., 2007)

The Southern Rift Valley, situated in the Southwestern part of the country, is one of the areas, most severely affected with the trypanosomiais and annual losses to the livestock industry. This is believed to affect directly or indirectly the lives of over 5 million people in the region. About 25,000 km2 areas that is agriculturally suitable and potential land in the valley are infested by tsetse flies. In this part of the country nearly one million heads of cattle are currently at risk of trypanosomosis, and almost all domestic animals in and adjacent areas of the valley are at risk of acquiring the disease at any time (Bekele, 2004). Thus, priority for tsetse control has been given by Ethiopian Government and a programmed has been launched in 1997; then 'Southern Rift Valley of Ethiopia Tsetse Eradication Project' (SRVETEP) 1988-2000 (currently named as 'Southern Tsetse Eradication Project' STEP) was established (Bekele, 2004).

Hence, knowing the current status of the disease and its vectors and determining the changes that follows tsetse fly and trypanosomosis control measures on the livelihood of rural communities in the study area, is crucial to assess the impact of control programs both on the wellbeing human and animals and apply efforts towards combating the disease and reducing economic losses in the area. Therefore, taking into an account the above mentioned statements, the following objective was designed to conduct studies.

- To assess the perception of livestock farmers about trypanosomosis and tsetse flies and the impact of past tse-tse fly suppressive and trypanosomosis control interventions carried out by Southern Tsetse Eradication Project (STEP).

- To estimate the current prevalence of trypanosomosis.

- To identify the trypanosome species circulating in the studyarea.

- To determine post control vector density in the area. 


\section{Materials ANd Methods}

\subsection{Study Area}

The study was conducted from October 2015 to April 2016 in three purposively selected kebeles (Wezeqa, Kanchama and Shara) found in Arbaminchzuriaworeda, GamoGofa Zone, Southern Nationtions, Nationalities and People Regional State (SNNPRS). These kebeles are one of the intervention sites of the Southern Rift Valley Tsetse Eradication Project (STEP). The tsetse and trypanosomosis control interventions have been implemented in these areas by STEP since 1998 (in Kanchama and Wozeqa) and 2008 (in Shara). They were selected purposively due to their proximity to Arbaminch, ease of road accessibility and ability to talk local language. Geographically, Wezeqa, Kanchama and Shara are located at $37^{\circ} 33^{\prime} \mathrm{E}$ longitude \& $6^{\circ} 2^{\prime} 00^{\prime \prime} \mathrm{N}$ latitude, $37^{\circ} 53^{\prime} 41^{\prime \prime}$ E longitude and $5^{\circ} 9^{\prime} 72^{\prime \prime} \mathrm{N}$ latitude, and 37'59'04" E longitude $\& 6^{\circ} 0^{\prime} 51^{\prime \prime} \mathrm{N}$ latitude, respectively. Wozeka and Kanchama districts are located respectively at $34 \mathrm{~km}$ and $22 \mathrm{~km}$ on the Southern part of the Arbaminch along the way to South Omo (Jinka) while Shara is located at a distance of $14 \mathrm{~km}$ North West of Arbaminch town along the way to Welayita zone. Arbaminch is located at a distance of $505 \mathrm{Km}$ south of Addis Abeba and $208 \mathrm{Km}$ from the regional town, Hawassa. Geographically, it is situated at $37^{0} 5^{\prime}$ E longitude and $6^{\circ} \mathrm{N}$ latitude with altitude of $1200-3125 \mathrm{~m}$ above sea level. The annual rain fall ranges from $750-930 \mathrm{~mm}$ with mean average temperature is $30^{0} \mathrm{c}$. The town is situated in the well-known East African Rift valley and surrounded by Lake Chamo and Abaya as well as 'Nech-Sar' national park. The main occupation of the rural population is mixed farming system whereby crop and livestock are managed. Farmers found in and around Arbaminch commonly produce crops such as maize, coffee, banana, papaya, mangoe, avocado, inset, apple and others (GZARDO, 2007).

\subsection{Study Population}

The study population constitutes 1) randomly selected livestock keeping households living in the study area and 2) randomly selected cattle of different age and sex category.

\subsection{Study Design and Sampling Criteria}

The study was cross-sectional in nature and it was carried out in three kebeles of
Arbaminchzuriaworeda namely Wozeqa, Kanchama and Shara. Initially, the study was proposed to assess the impact of tsetse and trypanosomosis control interventions carried out by STEP by comparing the present prevalence of trypanosomosis and vector density with that of the preintervention baseline data. However, due to the absence of adequate baseline parasitological and entomological data record and because only the data of the year 2010 was available for these three districts, the study was redesigned to see the difference in prevalence of bovine trypanosomosis and vector density between year 2010 and 2016. The questionnaires survey were was undertaken to obtain information on the perception of livestock owners towards tsetse fly and trypanosomosis, their effects on cattle, herd composition and treatment of the disease. It was also intended to assess the impact of tse-tse fly suppressive interventions on aspects of livestock management, trypanosomosis and its vector before interventions and atpresent.

\subsection{Sampling Technique and Sample Size determination}

For questionnaire survey and parasitological study, the study subjects, livestock keeping households and cattle population were selected by simple random sampling technique, while purposive sampling technique was used in selecting the three kebeles.

The total number of animals required for the study was calculated based on the formula given by Thrusfield (2005).

$$
\mathrm{n}=\frac{1.96^{2}[\mathrm{P} \text { exp- (1-P exp) }]}{\mathrm{d}^{2}}
$$

Where $\mathrm{n}$ is the required sample size, Pexp is the expected prevalence and $\mathrm{d}$ is the desired absolute precision.

For parasitological study, the expected prevalence was estimated from the previous recent prevalence studies made by Zecharias and Zeryehun (2012) who reported a prevalence of $27.5 \%$ in selected kebeles of Arbaminch. By taking an expected prevalence as $27.5 \%$ considering a $5 \%$ absolute precision and at $95 \%$ confidence level the sample size was computed to be 306. But to increase the precision, the sample size was increased to 360. For questionnaire survey, 216 households were randomly sampled from the study area, for the reason of time and resource available for the 
study. Tsetse flies were sampled by deploying about 15 NG2U (five in each kebele) baited with three-week old bovine urine in one dispensing bottle. Traps were set at approximate intervals of 200-250 meters. All trap positions were geo-referenced (by use of hand- held GPS) and altitude, latitude, longitude and vegetation type was recorded.

\subsection{Study Methodology}

\subsubsection{Questionnaire Survey}

A structured questionnaire survey was conducted on 216 respondents (cattle owners) to gather information with regard to their perception about the impact of tsetse and trypanosomosis control interventions undertaken by STEP in their localities. Interviews were held with local community members, including livestock and crop farmers, women and community leaders during field trips to tsetse and trypanosomiasis infested areas. Respondents were randomly selected from the households, who are residents of the district by informing them about purpose of the study. The questionnaires were administered by face to face discussion. The questionnaire format is attached in annexIII.

\subsubsection{Parasitological Survey}

For parasitological examination, blood sample was collected from ear vein of 360 cattle using heparanized micro-haematocrit capillary tube and the packed cell volume (PCV) was determined. During blood collection the necessary bio-data of each animal (the origin, age, sex, body condition, breed, management, herd size, coat color, temperature and general health condition) of each study animal was recorded. The capillary tube was filled with $2 / 3$ volume of blood.

The capillary tube was then sealed on one side with Cristaseal and transferred to a haematocrit centrifuge and spun for $5 \mathrm{~min}$ at 1200 revolutions per minute. The centrifuged capillary tube was measured on a haematocrit reader to estimate the PCV. It was cut at $1 \mathrm{~mm}$ below the buffy coat and the contents of the tube was expressed onto a slide, mixed and covered with a $22 \mathrm{~mm} \times 22 \mathrm{~mm}$ cover slip. The slide was examined with a 40x objective lens using microscopy to detect the presence of motile trypanosomes. For the purpose of species identification, a thin blood smear was prepared from the buffy coat for those samples that were positive on buffy coat examination and were stained with Giemsa stain and examined under a microscope using the oil immersion 100x objective lens. (Leak, 1998)

\subsubsection{Entomological Study}

For the entomological study, tsetse flies were collected by using trap in different positions of the study areas. The apparent densities of tsetse and biting flies were determined based on the mean fly catches in traps baited with cow's urine. NGU traps (named after Nguruman where it was developed) with a monotonically shape were positioned at approximate intervals of 200 to $250 \mathrm{~m}$ and left in position for three days (72hrs). The flies' catches per trap were identified, counted and apparent fly densities per trap per day (f/t/d) were recorded. The species of tsetse fly was identified based on morphological characteristics while other biting flies was identified according to morphological characteristics such as size, color, wing venation and proboscis at the genus level (Marquardt et al.,2000)

\subsection{Data Management and Analyses}

Microsoft Excel spread sheet program were used to manage the raw data obtained from hematological result, microscopic examinations, entomological study and questionnaire survey. Both SPSS and STATA statistical analysis tools were used to analyze and interpret the data. Descriptive statistics (frequency, percentage, and mean) were used to summarize qualitative data. Pearson's chi-square test was applied to analyze the association between prevalence of trypanosome infection and various host and environmental factors. Student's t-test was used to analyze the difference in mean PCV value between parasitaemic and aparasitaemic animals. Throughout the analysis, p-value < 0.05 was considered to have statistically significant difference.

\section{Results}

\subsection{Questionnaire Survey}

A pretested questionnaire was administered to 216 livestock-keeping households randomly selected from three kebeles in ArbaminchZuria district to assess the impact of tsetse fly suppression interventions carried by Southern Rift Valley Tsetse Eradication Project (STEP). It was also aimed to assess the perception of livestock keepers towards trypanosomosis and its vectors. The distribution of the study subjects based on demographic and other characteristics has been shown in Table 1 . 
Bovine Trypanosomosis: Prevalence, Vector Density and Livestock Farmers' Perception on the Impact of Trypanosomosis and Tsetse Control Interventions in Arbaminchzuriaworeda, Southern Ethiopia

Table1: Demographic characteristics of the study participants $(N=216)$

\begin{tabular}{|l|l|l|l|}
\hline \multicolumn{1}{|c|}{ Factors } & \multicolumn{1}{|c|}{ Category } & \multicolumn{1}{c|}{ No } & \multicolumn{1}{c|}{ Proportion (\%) } \\
\hline Kebeles & Wozeqa & 73 & 33.8 \\
\hline & Shara & 55 & 25.4 \\
\hline Sex & Kanchama & 88 & 40.7 \\
\hline & Male & 72 & 33.3 \\
\hline Age & Female & 144 & 66.6 \\
\hline & $20-30$ & 81 & 37.5 \\
\hline & $30-50$ & 102 & 47.2 \\
\hline Origin & $>50$ & 33 & 15.2 \\
\hline & Born in the current locality & 152 & 70 \\
\hline How long keeping livestock & Came from another area & 64 & 30 \\
\hline & $<20$ years & 162 & 75 \\
\hline Production system & $>20$ years & 54 & 25 \\
\hline & Extensive & 209 & 96.7 \\
\hline
\end{tabular}

Table 2 shows the results of questionnaire survey on the perception of the respondents towards trypanosomosis and its vectors. Accordingly, about $99 \%$ of the respondents knew that trypanosomosis is transmitted by tsetse fly bite and a higher proportion responded that the incidence of the disease is higher in the early rainy $(54.6 \%)$ and during the rainy seasons $(86.1 \%)$. Also a higher proportion of respondents $(69.4 \%)$ mentioned that the incidence of trypanosomosis is lower during the dry season.

Regarding the animal species frequently affected by trypanosomosis, $65.3 \%$ of the respondents replied that it is the problem of

Table2: Perception of the study participants about trypanosomosis and its vectors $(N=216)$

\begin{tabular}{|c|c|c|c|}
\hline Description & Options & $\mathbf{N}$ & Proportion (\%) \\
\hline \multirow{4}{*}{ How is trypanosomosis transmitted } & Contact & 17 & 7.9 \\
\hline & Inhalation & 29 & 13.4 \\
\hline & Tsetse fly bite & 214 & 99.1 \\
\hline & Ingestion of contaminated feed & 30 & 13.9 \\
\hline \multirow{2}{*}{$\begin{array}{l}\text { Occurrence of trypanosomosis at } \\
\text { early rainy season }\end{array}$} & High incidence & 118 & 54.6 \\
\hline & Low incidence & 97 & 44.9 \\
\hline \multirow[t]{2}{*}{$\begin{array}{l}\text { Occurrence of trypanosomosis at } \\
\text { rainy season }\end{array}$} & No incidence High incidence & $\begin{array}{l}1 \\
186\end{array}$ & $\begin{array}{l}0.4 \\
86.1\end{array}$ \\
\hline & Low incidence & 29 & 13.4 \\
\hline \multicolumn{2}{|l|}{ No incidence } & 1 & 0.4 \\
\hline \multicolumn{2}{|l|}{ Highincidence } & 17 & 7.8 \\
\hline \multicolumn{4}{|c|}{ Occurrence of trypanosomosis at dry season } \\
\hline & Low incidence & 150 & 69.4 \\
\hline & No incidence & 49 & 22.7 \\
\hline \multirow{2}{*}{ Which species are affected? } & Cattle only & 75 & 34.7 \\
\hline & Cattle, sheep, goats and equine & 141 & 65.3 \\
\hline \multirow{2}{*}{$\begin{array}{l}\text { Which symptoms are observed in } \\
\text { diseased animal? }\end{array}$} & Chancre & 120 & 55.6 \\
\hline & Fever & 155 & 71.8 \\
\hline
\end{tabular}

The result of assessment of the respondent's perception about the impact of trypanosomosis and tsetse fly control interventions on agricultural production and fly density has been presented in Table 3.

Regarding the agricultural activities, $86.1 \%$ of the respondents were using oxen for traction before the launching of the intervention but now cattle, sheep, goats and equidae while $34.7 \%$ responded that the disease affects cattle only. As to the symptoms of trypanosomosis, 55.6 $95.4 \%$ of the respondents knew each of the common clinical signs of the disease they were asked. The vast majority of the respondents were aware that trypanosomosis causes reduction in milk production (95.4\%), recumbency $(92.1 \%)$, emaciation $(89.4 \%)$, and abortion $(87.5 \%)$. Regarding the ecology for breeding of tsetse flies the majority of the respondents (96.8\%) replied that forest vegetation is the most favourable and only $35.2 \%$ mentioned savanna grass land a conductive environment. this proportion has increased to $94 \%$. On the other hand the proportion of respondents using hand tools for land cultivation has been reduced 
Bovine Trypanosomosis: Prevalence, Vector Density and Livestock Farmers' Perception on the Impact of Trypanosomosis and Tsetse Control Interventions in Arbaminchzuriaworeda, Southern Ethiopia

from $24.5 \%$ before intervention to $6.5 \%$ at present. The average land used for crop production before the intervention was 1.52 hectares but at present it has been increased to 2 hectares. The average number of animals owned before intervention was 12.3 but now it is 13.6 animals per household. The average number of animals dies from trypanosomosis per annum has been reduced from 4.3 before intervention to 1 per household at present. As to the frequency of trypanocide use, about $52.3 \%$ respondents agreed that it has been reduced at present but 47.7\% said same as before. Regarding the benefits obtained from interventions, the majority of the respondents mentioned that there is reduction in animal mortality (92.6\%) and tsetse disturbance $(83.3 \%)$, and increment in livestock size. Moreover $32.9 \%$ and $23.6 \%$ respondents replied that there is reduction in drug cost expenditure and increment in milk production, respectively. Regarding the distribution of tsetse flies, $56.5 \%$ respondents mentioned that they have seen flies biting their animals in the currents year but $85.7 \%$ agreed that the burden has been reduced due to the interventions.

Table3: Assessment of the respondent's perception about the impact of tsetse and trypanosomosis control intervention on agricultural production and fly density

\begin{tabular}{|c|c|c|c|}
\hline Description & Responses & Unit & Qty \\
\hline \multirow{2}{*}{ Use of oxen for traction } & Before intervention & $\%$ respondents & 86.1 \\
\hline & At present & $\%$ respondents & 94 \\
\hline \multirow[t]{2}{*}{ Use of hand tools for cultivation } & Before intervention & $\%$ respondents & 24.5 \\
\hline & At present & $\%$ respondents & 6.5 \\
\hline \multirow{2}{*}{$\begin{array}{l}\text { Land used for crop production in } \\
\text { hectare (mean) }\end{array}$} & Before intervention & $\mathrm{Ha}$ & 1.5 \\
\hline & At present & $\mathrm{Ha}$ & 2 \\
\hline \multirow[t]{2}{*}{ Average number of animals owned } & Before intervention & No & 12.3 \\
\hline & At present & No & 13.6 \\
\hline \multirow{2}{*}{$\begin{array}{l}\text { Average number of animals die from } \\
\text { trypanosomosis per annum }\end{array}$} & Before intervention & No & 4.3 \\
\hline & At present & No & 1 \\
\hline \multirow[t]{2}{*}{ Frequency of trypanocides use at present } & Not reduced/same as before & $\%$ respondents & 47.7 \\
\hline & Reduced & $\%$ respondents & 52.3 \\
\hline \multirow[t]{5}{*}{ Benefits obtained after interventions } & Increment in milk Production & $\%$ respondents & 23.6 \\
\hline & Reduction in animal Mortality & $\%$ respondents & 92.6 \\
\hline & Increment in stock size & $\%$ respondents & 73.2 \\
\hline & $\begin{array}{llll}\begin{array}{l}\text { Reduction } \\
\text { Expenditure }\end{array} & \text { in } & \text { drug } & \text { cost } \\
\end{array}$ & $\%$ respondents & 32.9 \\
\hline & $\begin{array}{llll}\begin{array}{l}\text { Reduction } \\
\text { disturbance }\end{array} & \text { in } & \text { tsetse } & \text { fly } \\
\end{array}$ & $\%$ respondents & 83.3 \\
\hline \multirow{2}{*}{$\begin{array}{l}\text { Have you observed tsetse and other } \\
\text { biting flies feeding on your cattle }\end{array}$} & Yes & $\%$ respondents & 56.5 \\
\hline & No & $\%$ respondents & 43.5 \\
\hline \multirow[t]{3}{*}{ Tsetse fly burden in this year } & Increased & $\%$ respondents & 6.9 \\
\hline & Decreased & $\%$ respondents & 85.7 \\
\hline & The same as before & $\%$ respondents & 7.4 \\
\hline
\end{tabular}

Table4: Traditional methods to control and treat trypanosomiasis

\begin{tabular}{|c|c|c|c|c|c|c|c|c|}
\hline \multirow{2}{*}{$\begin{array}{lll}\text { Methods to control and treat } \\
\text { trypanosomiasis }\end{array}$} & \multicolumn{2}{|c|}{ Wozeqa (73) } & \multicolumn{2}{|c|}{$\begin{array}{l}\text { Kanchama } \\
\text { (55) }\end{array}$} & \multicolumn{2}{|c|}{ Shara $(88)$} & \multicolumn{2}{|c|}{ Total(216) } \\
\hline & No & $\%$ & No & $\%$ & № & $\%$ & № & $\%$ \\
\hline Avoiding grazing in watering points and forests & 6 & 8.2 & 3 & 5.4 & 8 & 9 & 17 & 7.8 \\
\hline Migrating animals to high land areas for grazing & 1 & 1.3 & 0 & 0 & 4 & 4.5 & 5 & 2.3 \\
\hline $\begin{array}{l}\text { Drenching animals with plant preparation } \\
\text { (tenadam, nechshinkurt (garlic) and others) }\end{array}$ & 12 & 16.4 & 9 & 16.3 & 15 & 17 & 36 & 16.6 \\
\hline $\begin{array}{l}\text { Thermocautery (burning animals with hot } \\
\text { metals for treatment of trypanosomiasis). }\end{array}$ & 5 & 6.8 & 7 & 12.7 & 8 & 9 & 20 & 9.2 \\
\hline Providing adequate feeds prior to rainy season & 0 & 0 & 3 & 5.4 & 3 & 3.4 & 6 & 2.77 \\
\hline
\end{tabular}
was shown that from 15 traps deployed at three kebeles, a total of 309 flies were caught. Of
Furthermore, all Glossina caught were identified to be Glossinapallidipes. The average tsetse fly 
Bovine Trypanosomosis: Prevalence, Vector Density and Livestock Farmers' Perception on the Impact of Trypanosomosis and Tsetse Control Interventions in Arbaminchzuriaworeda, Southern Ethiopia

density was 2.7 (range; $1-3.5$ ). The fly densities at Shara and Kanchamakebeles are almost similar and relatively higher than at Wezeqakebele. Regarding Tabanus and

Table5: Results of entomological survey presented by Kebele included in the study

\begin{tabular}{|l|l|l|l|l|l|l|l|l|l|l|l|l|}
\hline Kebele & Lat & Lon g & Alt & Veg & $\begin{array}{l}\text { No traps } \\
\text { deployed }\end{array}$ & $\begin{array}{l}\text { Trap } \\
\text { ping } \\
\text { days }\end{array}$ & \multicolumn{2}{|l|}{$\begin{array}{l}\text { G. } \\
\text { pallidipe } \\
\text { s caught }\end{array}$} & \multicolumn{2}{|l|}{$\begin{array}{l}\text { Other biting } \\
\text { flies caught, N }\end{array}$} & \\
\hline & & & & & & & & N & $\begin{array}{l}\text { FT } \\
\text { D }\end{array}$ & $\begin{array}{l}\text { Taba } \\
\text { nus }\end{array}$ & $\begin{array}{l}\text { Stomox } \\
y s\end{array}$ & $\begin{array}{l}\text { Tot } \\
\text { al }\end{array}$ \\
\hline Wezeqa & $\begin{array}{l}5.79- \\
5.82\end{array}$ & 37.45 & $\begin{array}{l}1121- \\
1135\end{array}$ & Bushland & 5 & 3 & 15 & 1 & 24 & 25 & 49 \\
\hline Shara & $\begin{array}{l}6.02- \\
6.05\end{array}$ & $\begin{array}{l}37.6 \\
0\end{array}$ & $\begin{array}{l}1182- \\
1189\end{array}$ & $\begin{array}{l}\text { Forest \& } \\
\text { bush land }\end{array}$ & 5 & 3 & 54 & 3.6 & 54 & 43 & 97 \\
\hline $\begin{array}{l}\text { Kancha } \\
\text { ma }\end{array}$ & $\begin{array}{l}5.91- \\
5.94\end{array}$ & $3747-$ & $\begin{array}{l}1135- \\
1188\end{array}$ & $\begin{array}{l}\text { Forest \& } \\
\text { bush land }\end{array}$ & 5 & 3 & 52 & 3.5 & 26 & 16 & 42 \\
\hline Overall & & & & & 15 & 3 & 121 & 2.7 & 104 & 84 & 188 \\
\hline
\end{tabular}

\subsection{Results of Parasitological Survey}

From the total of 360 blood samples screened by buffy coat examination, $6(1.7 \%)$ were found to be positive for trypanosomes. The highest prevalence was recorded at Kanchama $(2.5 \%)$ followed by Shara $(1.7 \%)$ and the lowest at

Table6: Prevalence of trypanosome infection based on the Kebele of study

\begin{tabular}{|l|l|l|l|l|l|l|l|}
\hline \multicolumn{1}{|c|}{ Kebele } & \multirow{2}{*}{$\begin{array}{c}\text { No animals } \\
\text { examined }\end{array}$} & \multirow{2}{*}{$\begin{array}{c}\text { No. animals } \\
\text { positive }\end{array}$} & Prevalence (\%) & $\chi^{2}$ & $\mathbf{p}$ & \multicolumn{2}{|c|}{ Trypanosome spp } \\
\cline { 6 - 9 } & & & & & T. vivax & T. congolense \\
\hline Wezeqa & 120 & 1 & 0.8 & 1.07 & 0.301 & - & 1 \\
\hline Shara & 120 & 2 & 1.7 & 0.19 & 0.665 & - & 2 \\
\hline Kanchama & 120 & 3 & 2.5 & Ref & & 1 & 2 \\
\hline Overall & 360 & 6 & 1.7 & & & $1(16.7 \%)$ & $5(83.3 \%)$ \\
\hline
\end{tabular}

Table 7 presents the results of analysis of trypanosome infection with various host and environmental factors. The prevalence of trypanosome infection was relatively higher in cattle with poor BCS $(3.6 \%)$ than in those with moderate BCS $(0.5 \%)$ but the difference was not significant $(\mathrm{p}>0.05)$ while no infection was observed in animals with good BCS. The animals examined were categorized in to three

Wezeqa $(0.8 \%)$. However, the difference in prevalence between the three kebeles was not statistically significant $(p>0.05)$. The species of trypanosome identified were $\mathrm{T}$. congolense and T. vivax at a proportion of of $83.3 \%$ and $16.7 \%$, respectively (Table 6).

age groups $(<1$ year, 1-3 year and $>3$ year) to see whether age has any influence on the disease prevalence. No infection was found in animals $<1$ while the difference in the prevalence of infection between cattle of 1-3 (2.8\%) and >3yr $(1.6 \%)$ age groups was not significant $(\mathrm{p}>$ $0.05)$. Likewise the variation in the prevalence of infection between different altitudes was not significant $(\mathrm{p}>0.05)$
Stomoxys, the caught for both flies is substantially higher in Shara than the other kebeles

Table7: Association of trypanosome infection with different risk factors

\begin{tabular}{|l|l|l|l|l|l|c|}
\hline \multicolumn{1}{|c|}{ Factor } & \multicolumn{1}{c|}{ Category } & \multicolumn{1}{c|}{ Total No } & No positive & Prevalence (\%) & $\chi^{\mathbf{2}}$ & $\boldsymbol{p}$ \\
\hline Sex & Female & 186 & 3 & 1 & & \\
\hline & Male & 174 & 3 & 1.7 & 0.01 & 0.934 \\
\hline Age & $\leq 1$ year & 33 & - & - & - & - \\
\hline & $1-3$ year & 72 & 2 & 2.8 & & \\
\hline & $>3$ year & 254 & 4 & 1.6 & 0.44 & 0.506 \\
\hline Herd size & $\leq 10$ & 250 & 6 & 2.4 & - & - \\
\hline & $>10$ & 110 & - & - & - & - \\
\hline BCS & Good & 27 & - & - & - & - \\
\hline & Moderate & 193 & 1 & 0.5 & - & - \\
\hline & Poor & 140 & 5 & 3.6 & 2.25 & 0.134 \\
\hline Altitude & 1185 & 120 & 1 & 0.8 & 1.07 & 0.301 \\
\hline & 1197 & 120 & 2 & 1.7 & 0.19 & 0.665 \\
\hline & 1202 & 120 & 3 & 2.5 & Ref & \\
\hline Breed & Cross & 4 & - & - & - & - \\
\hline
\end{tabular}


Bovine Trypanosomosis: Prevalence, Vector Density and Livestock Farmers' Perception on the Impact of Trypanosomosis and Tsetse Control Interventions in Arbaminchzuriaworeda, Southern Ethiopia

\begin{tabular}{|l|l|l|l|l|l|l|}
\hline & Local & 356 & 6 & 1.69 & 0.0686 & 0.793 \\
\hline Management & Grazing & 334 & 6 & 1.80 & - & - \\
\hline & Zero-grazing & 26 & - & - & - & - \\
\hline
\end{tabular}

The analysis of PCV value in the animals examined for trypanosome infection showed that the mean PCV of the parasitaemic cattle was $22.7 \%$ whilst the mean PCV of the

aparasitaemic cattle was $21.6 \%$. However, the difference in mean PCV between parasitaemic and aparasitaemic animals was not statistically significant ( $\mathrm{p}>0.05)$ (Table 8).

Table8: The difference in mean PCV (\%) between parasitaemic and aparsitaemic animals

\begin{tabular}{|l|l|l|l|l|l|l|l|l|}
\hline $\begin{array}{l}\text { Infection } \\
\text { status }\end{array}$ & No & $\begin{array}{l}\text { Animals with PCV } \\
<\mathbf{2 4 \%} \mathbf{N}(\boldsymbol{\%})\end{array}$ & $\begin{array}{l}\text { Mean PCV } \\
(\boldsymbol{\%})\end{array}$ & SE & $\begin{array}{l}\text { 95\% CI for } \\
\text { meanPCV }\end{array}$ & t & $\mathbf{p}$ \\
\hline Aparasitaemic & 337 & $230(68.2)$ & 21.6 & 0.3 & $21.0-22.2$ & -0.49 & 0.624 \\
\hline Parasitaemic & 6 & $3(50)$ & 22.7 & 2.2 & $17.1-28.3$ & & \\
\hline
\end{tabular}

3.4. Comparison of the Present and the 2010 Tsetse Density and Trypanosomosis Prevalence

Because of the absence of the pre intervention data, the present entomological survey result was compared with that conducted in 2010 at

Table9: Comparison of tsetse density between 2010 and 2016 in the three kebeles surveyed, Arbaminchzuriaworeda

\begin{tabular}{|l|l|l|l|l|l|l|l|l|l|l|}
\hline Kebeles & \multicolumn{2}{|c|}{$\begin{array}{c}\text { No of traps } \\
\text { deployed }\end{array}$} & \multicolumn{2}{c|}{$\begin{array}{c}\text { Duration (In } \\
\text { days) }\end{array}$} & \multicolumn{2}{c|}{$\begin{array}{c}\text { Tsetse species } \\
\text { (G.pallidipes) }\end{array}$} & \multicolumn{2}{|c|}{ Apparent density } & \multicolumn{2}{c|}{$\begin{array}{c}\text { Other biting } \\
\text { flies }\end{array}$} \\
\hline & 2010 & 2016 & 2010 & 2016 & 2010 & 2016 & 2010 & 2016 & 2010 & 2016 \\
\hline Wezeqa & 5 & 5 & 3 & 3 & 44 & 15 & 2.93 & 1.00 & 7 & 49 \\
\hline Kanchama & 5 & 5 & 3 & 3 & 176 & 54 & 11.73 & 3.60 & 11 & 42 \\
\hline Shara & 5 & 5 & 3 & 3 & 303 & 52 & 20.20 & 3.46 & 173 & 97 \\
\hline Overall & 15 & 15 & 3 & 3 & 523 & 121 & 11.6 & 2.7 & 191 & 188 \\
\hline
\end{tabular}

As with entomological survey, it was not possible to find the pre-intervention trypanosomosis prevalence data for the three kebeles included in the study. Thus, the present prevalence was compared with the data obtained from a survey in 2010 .

Table10: Analysis of the prevalence of trypanosome infection between 2010 and 2016 in three kebeles of Arbaminchzuriaworeda

\begin{tabular}{|l|l|l|l|l|l|l|l|l|}
\hline Kebeles & Sample size & & \multicolumn{2}{|c|}{ No positive } & \multicolumn{2}{c|}{ Prevalence (\%) } & \multicolumn{2}{c|}{ Difference in prevalence } \\
\hline & $\mathbf{2 0 1 0}$ & $\mathbf{2 0 1 6}$ & $\mathbf{2 0 1 0}$ & $\mathbf{2 0 1 6}$ & $\mathbf{2 0 1 0}$ & $\mathbf{2 0 1 6}$ & $\chi^{\mathbf{2}}$ & $\mathbf{P}$ \\
\hline Wezeqa & 73 & 120 & 4 & 1 & 5.47 & 0.83 & 3.88 & 0.049 \\
\hline Kanchama & 96 & 120 & 5 & 3 & 5.20 & 2.50 & 1.09 & 0.296 \\
\hline Shara & 72 & 120 & 5 & 2 & 6.9 & 1.66 & 3.54 & 0.060 \\
\hline Overall & $\mathbf{2 6 1}$ & $\mathbf{3 6 0}$ & $\mathbf{1 1}$ & $\mathbf{6}$ & $\mathbf{4 . 2 1}$ & $\mathbf{1 . 6 6}$ & $\mathbf{3 . 7 0}$ & $\mathbf{0 . 0 5 4}$ \\
\hline
\end{tabular}

\section{DISCUSSION}

Initially, this study was proposed to determine post control prevalence of bovine trypanosomosis and vector density in the study areas and to compare the current result from parasitological and entomological survey with that of the base line data gathered before the onset of tsetse and trypanosomosis control interventions. However, during the course of the study I was not able to get the baseline data from record. Therefore, due to the absence of the base line data, the present prevalence of bovine trypanosomosis and vector density was the same kebeles deploying equal number of traps for 3 days to see the impact of tsetse suppression interventions. It was noticed that there is substantial reduction in tsetse density in all of the kebeles surveyed between 2010 and 2016 (Table 9).
In all the kebeles, the present prevalence is lower than that obtained from the 2010 survey; however, statistically significant difference was noted only in Wezeqakebele $(\mathrm{p}<0.05)$ (Table 10).

compared with the 2010 data which was the only information available in the record for the three kebeles included in the present study.

The present questionnaire survey conducted to assess the community's perception about tsetse flies and trypanosomosis has shown that the respondents have a high level of awareness about the method of transmission, clinical signs and effect of trypanosomosis on animal production. Regarding their perception about the impact of tsetse and trypanosomosis control interventions by STEP, the majority of the respondents agreed that there is reduction in 
animal mortality rate per annum and tsetse density due to the interventions implemented, although they mentioned that the disease and vectors are still seen at a low level. Moreover, a considerable proportion of the respondents replied that there is increment in milk production and reduction in the cost they used to incur to purchase trypanocidal drugs.

Almost all (99.1\%) the respondents in the study area were aware of the causal association between tsetse flies (and other biting flies) and bovine trypanosomosis. Most of livestock owners' are familiar with different clinical signs of trypanosomosis. They emphasized that low milk production, recumbency, emaciation, abortion, swelling of LN, and fevers are the most frequently seen signs of the disease. The present finding is in agreement with a similar work conducted by Tadesse and Getaneh (2015) who reported that the majority of livestock owners surveyed were aware of the same symptoms of the disease in Bure and Womberma districts of West Gojjam Zone. Moreover, similar studies conducted in tsetse infested areas of Ethiopia (Tesfayeet al., 2011; Seyoum, 2012) have also revealed that most of the interviewed livestock farmers were able to mention the common symptoms that are used as diagnostic tool for trypanosomosis suspected cases.

Though, the level of precision depends on the experience of livestock keepers, most farmers could determine clinical signs suggestive of bovine trypanosomosis that are commonly described for the disease (Holms et al., 2004). Regarding the animal species frequently affected by trypanosomosis, $65.3 \%$ of the respondents replied that it is the problem of cattle, sheep, goats and equidae while $34.7 \%$ responded that the disease affects cattle only. During the field survey, perception of the livestock owners on seasonality of trypanosomosis and tsetse fly challenges was also assessed. Interviewees have declared that trypanosomosis and tsetse fly challenges have wide seasonal variations. About $54.6 \%$ of the respondents explained that the incidence of trypanosomosis and its vectors is higher at the beginning of long rainy season and the majority of the respondents $(86.1 \%)$ mentioned that the incidences reach peak level during rainy season in terms of profound morbidity and mortality effect of the disease, fly density and fly nuisance effect. On the other hand, $69.4 \%$ of the respondents reported that the challenges of trypanosomosis and its vectors become mild in the dry season. These results are consistent with a previous study (Dagnachew, 2004) in which the respondents declared the occurrence of trypanosomosis is throughout the year but major infections are observed after rainy season and after short rainy season. Regarding the ecology for breeding of tsetse flies the majority of the respondents (96.8\%) replied that forest vegetation is the most favourable. In agreement with the present finding, it has been stated that the female tsetse fly finds a suitable place to lay the larva during rainy (wet) season or wet regions such as rain forest, where there is general dampness everywhere (Robertson, 2004).

The tsetse and trypanosomosis control interventions implemented by STEP include the use of trypanocides to treat the sick animals and for prophylaxis, spraying of livestock with pyrethroids (delitametherines), arial spray, and use of treated traps and targets. Besides these, the livestock owners use various traditional methods to control and treat trypanosomosis. These include; avoiding grazing in the watering points and forests, migrating animals to high land areas for grazing, drenching of plant preparation (tenadam (Rue), nechshinkurt (Garlic) and others) and burning animals with hot metals). However, there is no data to support how far these traditional practices are helping in reducing the incidence of trypanosomosis and these have to be elucidated by future studies. Nonetheless, the practice of burning animals with hot iron has detrimental effect on the health of animals and quality of their hides and thus, should be avoided through education of the livestock keepers.

Regarding changes in the agricultural activities, a higher number of respondents in the study area agreed for an increment in land used for crop production and livestock herd size following interventions. This is evidenced by the fact that the average land used for crop production has increased from 1.52 hectare before interventions to 2 hectare per household at present. Similarly the average number of animals owned per household has shown growth from 12.3 before intervention to 13.6 at present. Furthermore, it was observed that the proportion of respondents using oxen for traction has been increased from $86.1 \%$ before intervention to $94 \%$ post intervention. Likewise, the proportion of respondents using hand tools for land cultivation has been reduced from $24.5 \%$ before 
intervention to 6.5 after intervention. This result concords with Brent (1999) who stated that trypanosomiasis control interventions result in improvement of livestock management, particularly on the number of livestock kept by farmers and land use. It is clear that animal trypanosomiasis reduces work efficiency of oxen for cultivation, reducing access to animal traction (Swallow, 2000). According to the questionnaire survey result, the average number of animals dying from trypanosomosis before intervention was 4.3 per annum but reduced to only1 at present time. Furthermore, 52.3\% of the respondents replied that the frequency trypanocides use at present has reduced.

This observation is in line with the reports of Omotainse et al. (2004) who declared that cattle mortality is significantly higher in the tsetse challenge areas than in the free areas or controlled areas. Similarly, the finding was in agreement with the reports of Kamuanga et al. (2001) in Burkina Faso that suggests removal of tsetse challenge could significantly improve livestock production. Kamuanga et al. (2001) also reported a $56 \%$ reduction in overall cattle mortality in southern Burkina Faso owing to the control of tsetse flies. In our country, reduction of $72 \%$ in cattle mortality (Regassa, 2004) and $57 \%$ in mortality of calves (Rowland set al., 1999) was reported in areas where tsetse control measures were applied.

Regarding the benefits obtained from the interventions, $83.3 \%, 92.6 \%, 73.2 \%$ and $32.9 \%$ of the respondents agreed that they had noticed reduction in tsetse fly disturbance, reduction in animal mortality, increment in stock size and frequency of cattle fattening, and reduction in cost expenditure for drugs, respectively. Consistent with the current findings, all of these benefits were reported by previous studies (; Brent, 1999; Bekele, 2004; Samdiet al., 2010) as impacts observed following tsetse control measures. In the present study, a total of 121 tsetse flies were caught in 15 NGU traps deployed and all of these were found to be G.pallidipes. The overall apparent sets flies density in study area was 2.7 flies /trap/day. This result is considerably lower than that reported in 2010 study in the same area, i.e. 11.6 flies /trap/day and indicates that the tsetse control interventions implemented in the area had positive impact in reducing tsetse density. Similarly the present overall apparent tsetse flies density is appeared to be lower than the one reported by Tekaet al. (2010) which is 14.97 flies /trap/day in selected villages of Arbaminchzuriaworeda. In contrast, the current finding is higher than the observations of Muturiet al. (2000), Tafeseet al. (2012) and Lelisaet al. (2015) who reported about 1.4 flies /trap/day in the southern rift valley of Ethiopia, 1.45fly/trap/dayin East Wollega, and 0.06fly/ trap/dayin Mandura district, respectively. Glossinapallidipes was the only species of tsetse detected in the study area and this finding is in agreement with all of the tsetse fly surveys conducted in southern rift valley (Bekele et al., 2010; and Eyobet al., 2011). Regarding the other biting flies, a total of 188 Tabanus and Stomoxys were caught in the current study. This result is much closer to the 191 flies caught in 2010 in the same study area and this shows that the interventions had no significant impact in reducing the density of these flies and there is still a risk of mechanical transmission of some Trypanosome spp in the area through these blood sucking flies.

In general, the dramatic reduction of the prevalence of trypanosome infection and mean apparent density of the tsetse flies following interventions at study area may be attributed to the considerable suppression of fly population by the measures undertaken by STEP. However, the relatively higher apparent fly density observed in the current study than some reports from other areas and the absence of significant change in the density of mechanical vectors necessitates the need for strengthening feasible vector and trypanosomosis control interventions in the area so as to further improve livestock production and agricultural development.

The overall prevalence of trypanosome infection observed in the current study was $1.7 \%$ and no significant difference was noted between the kebeles included in the study. Although the current overall prevalence is lower than the 2010 data of $4.2 \%$, the difference was not statistically significant $(\mathrm{p}>0.05)$. But when the data was analyzed at kebele level, a significant difference $\quad(p<0.05)$ was noted for Wezeqakebele. When compared with previous studies conducted in the same district, the present overall prevalence or that at kebele level is considerably lower than a report of $28.1 \%$ from Elgo-fango (Zecharias, and Zeryehun, 2012), 26.9\% from Wozeka (Zecharias, and Zeryehun, 2012) and $4.43 \%$ from Fura and Eligo (Tekaet al., 2010) kebeles. The 
discrepancy between the current result and other reports might be due to the presence of study time gap in which application of well strategic method of tsetse control and treatment, expansion of cultivation which affects flies distribution, expansion of veterinary clinic and awareness of people towards the control and treatment of disease were improved.

The analysis of the present prevalence of trypanosome infection with host factors (sex, age, BCS and breed) and altitude showed lack of significant association with any of the factors considered ( $p>0.05)$. This result is in agreement with the findings of Tamiru et al. (2014) and Tadesse and Getaneh (2015), who assessed the associations of the disease with age, sex and body condition but found no significance association $(p>0.05)$. The lack of association of infection with sex is as expected but absence of association with age, BCS and breed may be due to the low prevalence of infection noted, that is, of the 360 cattle tested only six animals were found infected. In the present study, no animal below one year of age was found infected with trypanosomes and all the animals affected with were above one year of age. This may be due to the exposure of adult animals for the vector (tsetse fly) when they are left freely for grazing. It may also be due to immune suppression associated with stress factors such as lactation in the females and when oxen are traveling a long distance through tsetse challenge areas for drafting purpose Young animals are more resistant than adults to infection with trypanosomosis and they are not commonly exposed for the vector. The low prevalence in young animals may also be due to the natural protection to some extent by maternal antibodies (Fimmen, 1999). It was observed that all the positive animals were free ranging animals that travel a long distance through tsetse challenge areas.

The mean PCV (\%) of parasitaemic animals $(22.7 \pm 2.2)$ was lower than aparasitaemic animals $(21.6 \pm 0.3)$ but the difference was not significant $(\mathrm{p}>0.05)$. Taking average PCV $(\%)$ of $24 \%$ as cut-off value for cattle (Nseabasiet al., 2014), $68.2 \%$ of the aparasitaemic animals were found anemic. Apart from nutritional deficiencies, the detection of anemic in a large proportion of non infected animals might be due to the presence of other parasitic infection like haemoparasites and helminthiasis. The present result is in close agreement with the findings of Tamiru et al., (2014) who also reported lack of significant difference in mean PCV between parasitemic $(25.50 \%)$ and aparasitemic cattle $(25.20 \%)$. But the finding was in contrary with reports of Tekaet al., (2012) that studied the prevalence of bovine trypanosomosis and tsetse density in selected villages of Arbaminch and reported relatively lower mean PCV value in parastemic $(20.94 \%)$ animals than aparastemic animals $(23.55 \%)$.

But the study of Tekaet al., (2012) supports the current study having an overall mean PCV value blow the reference point $(\mathrm{PCV}>24)$. In the current study, the relative higher PCV value in parestemic animals than aparastemic animals may be due to the presence of small number of positive animals (low prevalence) that were appeared to have comparatively higher PCV value by chance.

Comparatively, the overall mean PCV value of the current study (22.13) is lower than mean PCV value computed from the data of the year 2010 (24.68\%), but closer to the report from Teka et al., 2014 who reported an overall PCV $22.24 \%$ in selected villages of Arbaminch. But the result was contrary to the findings of Bekele et al., (2010) in which, reduction in tsetse apparent density and trypanosomiasis prevalence in Ghibe resulted in significant increase in PCV values of cattle.

\section{CONCLUSION AND RECOMMENDATION}

The questionnaire survey conducted on the livestock keepers' in the study area provided important information on the disease situation, farmers 'perceptions about tsetse fly, and trypanosomosis and its impact. Livestock owners also identified the vector, tsetse fly and associated it with the disease trypanosomosis. They also have good knowledge on the suggestive signs of trypanosomosis and its impact on the agricultural activity and on the livelihood and wellbeing of cattle as well as on the owners themselves. According to the perception of the farmers, there is reduction in moratlity rate of animals from trypanosomosis, increment in milk production, reduction in costs incurred for trypanocidal drugs, increment in stock size and land used for crop cultivation, and reduction in tsetse density due to various interventions carried out by STEP. In general, the farmers were well aware of bovine trypanosomosis and its vector, seasonality, its impact, and benefits from intervention. The present entomological survey has revealed the existence of cyclical vector, Glossinapallidepes, 
in the study area at a density which is considerably lower than that reported in 2010 . Other biting flies which can serve as mechanical vectors of some trypanosome species were also detected. Also, the prevalence of trypanosome infection noted in the current study is very low. Therefore in view of the above conclusion, the following major points are recommended for further consideration by all concerned bodies

- The current activity of Southern Tsetse Eradication Project (STEP), the integrated use of control methods in the suppression of tsetse fly population should be strengthened to improve livestock production and agricultural development in the area.

- It is advisable to educate animal owners on the drawbacks of some traditional trypanosomosis control/ treatment techniques, appreciating the techniques that are scientifically feasible, and incorporating farmers' knowledge in designing and implementing of the intervention program in the areas.

- Further study is recommended to assess the situation with regards to the cause of an overall reduced mean PCV value in the non infected animals.

\section{REFERENCES}

[1] Abebe, G and Jobre, Y. (1996): Trypanosomosis: a threat to cattle production in Ethiopia. Revue de Médecine Vétérinaire, 147: 897-902.

[2] Abebe, G. (2005): Trypanosomosis in Ethiopia. Ethiopian Journal of Biological Sciences 4:75- 81.

[3] Bekele, J. (2004): Control of tsetse and trypanosomosis in the southern Rift valley (STEP) area: evaluation of Deltamethrin applications. MSc Thesis, Addis Ababa University, Faculty of Veterinary Medicine, Debrezeit, Ethiopia.

[4] Bekele, J., Asmare, K., Abebe, G., Ayelet, G., Gelaye, E. (2010): Evaluation of deltamethrin applications in the control of tsetse and trypanosomosis in the southern rift valley areas of Ethiopia. Veterinary Parasitology, 168:177-184.

[5] Brent, M. (1999): Impacts of trypanosomiasis on African agriculture. International Livestock Research Institute, Nairobi, Kenya Pp 3-10.

[6] Cecchi, G., Mattioli, R., Slingenbergh, J., Delarocque, and S. (2008): Land cover and tsetse fly distributions in sub-Saharan Africa. Med Vet Entol;22(4):364-73

[7] CSA (Central statistical Authority) (2011): Agricultural sample survey, report on livestock and livestock characteristics (Private peasant holdings), Addis Ababa, 2: 12-23

[8] Dagnachew, S. (2004): Epidemiology of bovine trypanosomosis in the Abbay basin areas of northwest Ethiopia. MSc thesis, Faculty of Veterinary Medicine, Addis Ababa University, Debrezeit, Ethiopia, Pp 64-75

[9] Dagnatchew, Z. (1982): Trypanosomiasis in Ethiopia. Proceedings of the 3rd International Symposium on Veterinary Epidemiology and Economics, Available at (www.sciquest.org.nz) Accessed date 12 May, 2016.

[10] Eyob, A., Mekuria, S., Regassa, A., Abebe, R. (2011): A cross-sectional study of equine trypanosomosis and its vectors in Wolayta zone, Southern Ethiopia. J. Vet. Med. Anim. Health, 3(2):21-26.

[11] Feldmann, U. Dyck. A., Mattioli, C. and Jannin, J. (2005): Potential impact of tsetse fly control involving the sterile insect technique. Sterile Insect Technique: Principles and Practice in Area-Wide Integrated Pest Management. Springer; the Netherlands: p. $701-723$.

[12] Fimmen, D., Mehlitz, F., Horchiners, E., Korb,S. (1999): Colostral antibodies and Trypanosomacongolense infection in calves. Trypanotolerance research and application, No, 116, Germany, Pp: 173-178

[13] Gebreyohannes, M. and Legesse, F. (2014): Epidemiological Study of Bovine Trypanosomiasis in WolisoWoreda, Ethiopia. J AnimSciAdv, 4(5): 833-838

[14] GZARDO, (2007): GamoGofa Zone Agricultural and Rural Development Office, Arbaminch, GamoGofa, Ethiopia.

[15] Holms, P., Maudlin, I, Miles, M. (2004): The trypanosomosis. Wallingford, International publishing, Pp: 1-634.

[16] Kamuanga, M., Sigue, H., Bauer, B. Swallow, B., D'ieteren, G. (2001): Farmer's perceptions of the impact of tsetse and trypanosomes and control on livestock production; evidence from the southern Burkina- Faso. Trop. Anim. Health. Prod., 2001, 33, 41-153

[17] Leak, S. (1998): Tsetse Biology and Ecology. Their role in the Epidemiology and Control of Trypanosomiasis. Pp204-215

[18] Lelisa, K., Damena, D., Kedir, M., Feyera, T. (2015): Prevalence of Bovine Trypanosomosis and Apparent Density of Tsetse and Other Biting Flies in Mandura District, Northwest Ethiopia. J VeterinarSciTechnol6: 2157-7579

[19] Marquardt, C., Demaree, C. Grieue, .B. (2000): Parasitology and vector biology, 2nd edn. Academic Press, London.

[20] Muturi, K., Msangi, S., Munstermann, S., Clausen, P., Getachew, A., Getachdew, T., Bergeine, B., Assefa,M. (2000): 
Trypanosomosis risk assessment in selected sites of the southern rift valley of Ethiopia. In: International Scientific Council for Trypanosomosis Research and Control (ISCTRC). Proceedings of the 25th meeting held in Mombassa, Kenya. OAU/STRC Publication, Pp 120-122.

[21] Nseabasi, N., Etim, E. Williams, U., Edem, E. Offiong, S. (2014): Haematological Parameters and Factors Affecting Their Values, Agricultural Science 2; 37-47

[22] OAU (Organinization of African Union) (2002): Trypanosomosis, Tsetse and Africa. The year book report. Tropical Medicine and International Health, 4; 21-45

[23] OIE (World Organization for Animal Health) (2008): Trypanosomosis (tsetse-transmitted) Terrestrial Manual. Available at (http://web.oie. int/eng/normes/mmanual/2008/pdf/2.04.18_trypa nosomosis.pdf). Accessed date 11 JUNE 2016

[24] Omotainse, S., Kalejaiye, P., Dede, A., Dada, J. (2004): The current status of tsetse andanima trypanosomiasis in Nigeria. Vom. J. Vet. Sci., 1:1-9.

[25] Radostits, O.M., Gray, C.G., Hinchcliff, K.W., Constable, P. (2007): Veterinary Medicine: A Text Book of the Disease of Cattle, Horses, Sheep, Pigs and Goats. Saunders Elsevier, London. Pp. 1531-1540.

[26] Regassa, F. (2004): Current epidemiological situation of bovine trypanosomosis in Limu shay Tsetse controlled area of Upper Didessa Valley. MSc Thesis, Faculty of Veterinary Medicine, Addis Ababa University, Ethiopia, Pp 21-34

[27] Robertson, H. (2004): Family: Glossinidae (tsetse-flies). Bio-diversity explorer Iziko, Museums of Cape Town, South Africa.

[28] Rowlands, G., Woudyalew,M., Leak, S., Nagda, S., D'ieteren, G.( 1999): Estimating the effects of tsetse control on livestock productivity: a case study in southwest Ethiopia. Trop. Anim. Health. Prod., 31,279-29 4.

[29] Samdi, S., Abenga, J., Attahir, A., Haruna, M., Wayo, B., Fajinmi, A., Sumayin, H.,.Usman, A., Hussaina, J., Muhammad, H., Yarnap, J., Ovbagbedia,R., Abdullahi,R(2010): Impact of Trypanosomosis on Food Security in Nigeria: A Review International Journal of Animal and Veterinary Advances 2(2): 47-50,
[30] Steinfeld, H., Wassenaar,T., Jutzi, S (2006): Livestock production systems in developing countries: status, drivers, trends. Animal Production and Health Division, Food and Agriculture Organization of the United Nations, VialedelleTerme di Caracalla, Italy Rev. sci. tech. 25 (2),505-516

[31] Swallow, B. (2000): Impact of Trypanosomiasis on African Agriculture. PAAT Technical and Scientific Series, FAO. Rome. Vol. 2, pp 3-5

[32] Tadesse, E and Getaneh, G. (2015): Prevalence of Bovine Trypanosomosis and Farmers Perception in the Management of Disease in Bure and Womberma Districts of West Gojjam Zone, North West Ethiopia, World J. Biol. Med. Science 2 (4), 42-56.

[33] Tafese, W., Melak, A., Fentahun, T. (2012): Prevalence of bovine trypanosomosisand its vectors in two districts of East Wollega Zone, Ethiopia. Journal of Veterinary Research 79: 34- 43.

[34] Tamiru, F., Mideksa, B., Kumar, R., Terfa, W. (2014): Post Control Survey on Prevalence of Bovine Trypanosomosis and Vector Distribution in Ameya District, South West Shewa, Ethiopia, Global Journal of Medical research: 14 (3): 2249-4618

[35] Taylor, A., Coop, L., Wall, L. (2007): Veterinary Parasitology, 3rded. UK. Black well Publishing, Pp; 44-102.

[36] Teka, W., Terefe, D., Wondimu, A. (2010): Prevalence study of bovine trypanosomosis and tsetse density in selected villages of Arbaminch. Ethiopia Journal of Veterinary Medicine and Animal Health 4:36-41.

[37] Tesfaye, D., Speybroeck, N., Deken, R. (2011): Economic burden of bovine trypanosomosis in three villages of Metekel zone, northwest Ethiopia Tropical animal health production, 44: 873-879

[38] Trusfield, M. (2005): Veterinary Epidemiology 3rd edition, United Kingdom. Black Wellseiences.Pp:626

[39] Zecharias, A. and Zeryehun, Z. (2012): Prevalence of Bovine Trypanosomosis in Selected District of Arba Minch, Snnpr, Southern Ethiopia, Global Veterinaria8 (2): 168-173.

Citation: Firew Lejebo, Esayas Balcha, Esayas Estiphanos, Gelano Gehano, Bovine Trypanosomosis: Prevalence, Vector Density and Livestock Farmers' Perception on the Impact of Trypanosomosis and Tsetse Control Interventions in Arbaminchzuriaworeda, Southern Ethiopia, ARC Journal of Animal and Veterinary Sciences. 2019; 5(4):9-21. doi: dx.doi.org/10. 20431/2455-2518.0504002.

Copyright: (c) 2019 Authors. This is an open-access article distributed under the terms of the Creative Commons Attribution License, which permits unrestricted use, distribution, and reproduction in any medium, provided the original author and source are credited. 